\title{
Parentalidade socioafetiva: um olhar da Psicologia
}

\author{
Socio-affective parenting: a look at Psychology \\ Crianza socio-afectiva: una mirada a la Psicología
}

Recebido: 22/07/2021 | Revisado: 29/07/2021 | Aceito: 12/08/2021 | Publicado: 15/08/2021

\author{
Geruza da Silva Medeiros \\ ORCID: https://orcid.org/0000-0003-1286-7042 \\ Universidade Franciscana, Brasil \\ E-mail: geruzameedeiros@gmail.com \\ Fernanda Pires Jaeger \\ ORCID: https://orcid.org/0000-0002-7094-7764 \\ Universidade Franciscana, Brasil \\ E-mail: fernandajaeger19@gmail.com
}

\begin{abstract}
Resumo
A psicologia jurídica, considerada uma disciplina ainda em construção, vem sendo cada vez mais utilizada no âmbito jurídico. O presente trabalho refere-se a uma revisão teórica acerca da temática da parentalidade socioafetiva, buscando conhecer os critérios envolvendo a definição dos profissionais da psicologia e seu posicionamento frente a esta realidade no meio jurídico, identificando possíveis intervenções do psicólogo frente a situações que envolvam a temática. A metodologia desta pesquisa engloba uma revisão de literatura com abordagem narrativa, considerada uma fundamentação teórica pertinente para a composições de artigos, dissertações, teses, como também trabalhos de conclusão de cursos. Os resultados diante da pesquisa apontaram a importância do trabalho da psicologia jurídica nos dias atuais, principalmente no que diz respeito ao Direito de Família e suas decorrentes mudanças em relação a definição de multiparentalidade. Em decorrência de modificações no sistema judiciário, foi colocado em ênfase a palavra afeto, levando em consideração os vínculos reais e indo além da filiação genética. Desta forma, percebe-se a necessidade da Psicologia desenvolver ferramentas e intervenções voltadas para esta nova realidade que se apresenta no contexto jurídico contemporâneo.
\end{abstract}

Palavras-chave: Filiação; Paternidade socioafetiva; Psicologia; Jurídico.

\begin{abstract}
Juridical Psychology, considered a discipline still under construction, has been increasingly used in the legal field. The present work refers to a theoretical review on the theme of socio-affective parenting, seeking to know the criteria involving the definition of psychology professionals and their position regarding this reality in the legal environment, identifying possible interventions of the psychologist in situations involving the thematic. The methodology of this research encompasses a literature review with a narrative approach, considered a relevant theoretical foundation for the composition of articles, dissertations, theses, as well as course completion works. The results of the research pointed out the importance of the work of legal psychology nowadays, especially with regard to Family Law and its resulting changes in relation to the definition of multiparenthood. As a result of changes in the judicial system, the word affection was emphasized, taking into account the real bonds and going beyond genetic affiliation. Thus, there is a clear need for Psychology to develop tools and interventions aimed at this new reality that presents itself in the contemporary legal context.
\end{abstract}

Keywords: Affiliation; Socio-affective paternity; Psychology; Legal.

\section{Resumen}

La psicología jurídica, considerada una disciplina aún en construcción, se ha utilizado cada vez más en el ámbito jurídico. El presente trabajo se refiere a una revisión teórica sobre el tema de la parentalidad socioafectiva, buscando conocer los criterios que involucran la definición de los profesionales de la psicología y su posición frente a esta realidad en el ámbito jurídico, identificando posibles intervenciones del psicólogo en situaciones que involucran la temática. . La metodología de esta investigación comprende una revisión de la literatura con enfoque narrativo, considerada un fundamento teórico relevante para la composición de artículos, disertaciones, tesis, así como trabajos de finalización de cursos. Los resultados de la investigación señalaron la importancia del trabajo de la psicología jurídica en la actualidad, especialmente en lo que respecta al Derecho de Familia y los cambios resultantes en relación a la definición de multiparentidad. Como resultado de modificaciones en el sistema judicial, se enfatizó la palabra afecto, teniendo en cuenta los vínculos reales y yendo más allá de la filiación genética. Por tanto, existe una clara necesidad de que la Psicología desarrolle herramientas e intervenciones dirigidas a esta nueva realidad que se presenta en el contexto jurídico contemporáneo.

Palabras clave: Afiliación; Paternidad socio-afectiva; Psychology; Legal. 


\section{Introdução}

A partir do século XX ocorreram diversas transformações em nossa sociedade, relacionadas aos papéis sociais de homens e mulheres, que acarretaram em mudanças significativas na constituição da família, o que contribuiu para a ampliação dos direitos individuais e das conquistas tecnológicas. Com isso, o padrão das relações familiares, que antes eram consideradas inadequadas, torna-se algo plural e em constante modificação.

De acordo com Costa (2009), ao longo da história, a família brasileira sofreu influência de diferentes povos, como o dos Romanos, que defendiam o conceito de família patriarcal, onde quem comandava a família era o pai, que por sua vez, era visto pelos filhos como uma figura distante afetivamente, conduzindo suas intervenções, por meio da repressão. Este conceito que foi transformado ao passar do tempo, resultou em impactos sociais ocorridos a partir do grande avanço industrial, cultural, entre outros. Nesta transição, deu-se o começo de um novo modelo familiar, compreendido como "família moderna". As caracterizações durante esse momento acarretaram diversas indagações relativas à designação de filiação, assim como qual a maneira correta de identificar a paternidade e quais critérios seriam de primazia. A ocorrência de alterações diante a concepção de parentesco, entre as discussões neste âmbito, aparecem em 1980 e com isso, surge um elemento a mais perante as leis, apresentando algo que teria um significado em relação ao indivíduo e aos vínculos que são criados em sua vida, que pode ser compreendido como afeto. Aspecto no qual passa a ser designado como socioafetivo da filiação.

Bastos (2010) cita o conceito de Pichon-Revière denominado de "Teoria do Vínculo", que possui um caráter social na medida em que sempre terá figuras internalizadas presentes em uma relação, uma estrutura triangular, ou seja, em toda relação existe uma presença sensorial corpórea humana, um terceiro. É considerado o vínculo como uma estrutura psíquica bastante complexa, pelo fato de que este dá ao sujeito a possibilidade de construir uma configuração de interpretação da realidade própria de cada um. O que podemos relacionar com o tema que está em discussão, a possibilidade de uma nova configuração familiar, referindo-se ao vínculo socioafetivo estabelecido. Segundo Trindade (2012) devemos ter consciência da importância da formação dos vínculos na constituição do sujeito, sendo o afeto como precursor da repersonalização da família, a partir disso, surge uma nova concepção familiar que elucida um lugar de privilégio para a composição dos afetos, intitulado essa nova concepção como Parentalidade Socioafetiva.

O presente trabalho refere-se a uma revisão teórica acerca da temática da parentalidade socioafetiva, no qual buscou caracterizar teoricamente e colocar em pauta os critérios de definição dos profissionais da psicologia diante do posicionamento frente a esse novo fenômeno no âmbito jurídico, como também identificar as possíveis intervenções e atuações do psicólogo em situações que envolvam a parentalidade socioafetiva, sendo assim problematizar a importância da articulação interprofissional entre a psicologia e o direito em situações de parentalidade socioafetiva. A pesquisa foi aprofundada a partir do ingresso e valorização da palavra "afeto" no judiciário, este que trouxe à tona uma nova visão em suas decisões, este artigo tem como objetivo pôr em pauta um tema considerado recente em nossa legislação, o tema da parentalidade socioafetiva, que também busca como objetivo servir como referência bibliográfica tanto a ciência da Psicologia, como também do Direito. Nessa perspectiva, considera-se importante buscar um entendimento sobre este fenômeno de forma mais ampla, evidenciando que pelo fato de ser um assunto atual, ainda temos poucos trabalhos envolvendo esta temática.

\section{Metodologia}

O presente trabalho foi caracterizado por meio da elaboração de uma revisão de literatura com abordagem narrativa. A revisão narrativa trata-se de um método de elaboração no qual não se utiliza critérios explícitos e sistemáticos para a investigação e análise crítica da literatura, sendo ela pertinente a fundamentação teórica de artigos, dissertações, teses, como também trabalhos de conclusão de cursos. Em comparação com a revisão sistemática, julgasse uma temática mais aberta, onde geralmente não 
parte de questão especifica bem definida, o que por sua vez não é exigido um protocolo rígido para sua composição, considerando a busca de suas fontes não pré-determinadas e especifica. (Universidade estadual paulista, 2015)

A revisão narrativa considera-se uma das formas de pesquisa em que utiliza fontes de informações tanto bibliográficas como eletrônicas, afim de obter resultados de pesquisas de outros autores que tem com o propósito de compor teoricamente um determinado objetivo. Refere-se a publicações mais amplas, pertinentes para descrever e discutir o desdobramento de um assunto estabelecido, na perspectiva teórica ou contextual. No entanto, as revisões narrativas não informam as fontes de informações utilizadas, a metodologia da busca das referências, como também o processos utilizados para a avaliação e seleção dos trabalhos, são constituídas por análises de literatura, publicadas bem como em livros, artigos de revistas impressas e/ou revistas eletrônicas na interpretação e análise crítica pessoal do autor (Rother, 2007).

Primeiramente, foi pesquisado artigos em bases de dados, utilizando-se de palavras chaves, como "filiação", "parentalidade socioafetiva", "psicologia" e "jurídico". Foram usados, para a construção desse trabalho, 8 artigos retirados de plataformas eletrônicas, como IBDFAM, SCIELO, Brazilian Journals, bem como publicações de artigos em revistas online, como a Revista Jurídica, Revista Psicologia, Ciência e Profissão e Revista CEJ, utilizou-se também informações obtidas no site do Conselho Federal de Psicologia, tal como uma jurisprudência retirada do site do Tribunal de Justiça. Foram incluído 8 livros da área da Psicologia, como também do Direito, disponibilizados na biblioteca institucional da Universidade, bem como do acervo pessoal a fim de colocar em pauta e explicar como a ciência psicológica percebe um aspecto que antes era apenas decidido pelo campo jurídico. Neste sentido, essa categoria de artigos, tem como papel fundamental para a educação, pelo fato de permitir ao autor adquirir e atualizar seu conhecimento sobre uma temática especifica em pouco tempo, a seguir serão apresentados os principais achados através da pesquisa realizada.

\section{Resultados e Discussão}

A partir da análise organizaram-se os resultados e discussões em capítulos que foram distribuídos da seguinte forma: "A Família no judiciário e filiação"; "A Psicologia no contexto judiciário" e "A Parentalidade socioafetiva”.

\subsection{Família no Judiciário e Filiação}

De acordo com o Código Civil de 1916, a definição de família, se dava como uma unidade de produção, fundamentalmente estabelecida nos laços patrimoniais, sendo o modelo único de família, os constituídos pelo casamento e apenas filhos legítimos. A partir da Constituição brasileira de 1988, foi definido que o objetivo fundamental da República era promoção do bem estar de todos, colocando em primeiro plano a preocupação com a dignidade, com a liberdade e a igualdade de cada cidadão (Silva \& Rovinski, 2012).

O Direito de Família tem buscado dar conta das demandas para assim adaptar-se às necessidades trazidas pelas mudanças sociais. Com a entrada do novo Código Civil (2002), certificou-se a valoração do afeto na estruturação do núcleo familiar. Nos artigos 1.593 e 1.596, sucedeu contribuições no reconhecimento e garantias à filiação que não fosse natural e de valoração de interesses pessoais em detrimento das questões patrimoniais. Quando o código civil (2002) foi modificado com a lei da guarda compartilhada, a legislação então passou a utilizar a palavra "afeto". Nesse sentido, o artigo 1.583 passa a definir o afeto nas relações com o genitor e com o grupo familiar, sendo este um marco para a definição da guarda unilateral (Silva \& Rovinski, 2012).

Deve-se salientar, ainda, a contribuição da legislação infraconstitucional na evolução do Direito da Família, podendo ser citados o Estatuto da Criança e do Adolescente (ECA, 1990) e o Estatuto do Idoso (Lei 10.741/2003), todos voltados a garantias de direitos quanto à integridade e ao bem-estar de seus signatários (Silva \& Rovinsk, 2012, p. 210). 
Segundo Silva e Rovinski (2012) a família no judiciário passou por uma grande busca de legitimação e reconhecimento de mudanças na sociedade moderna, apoiado pela dimensão jurídica, trazendo consigo a "judiciarização" das relações e dos conflitos interpessoais, ou seja, pode-se ter como base que nos dias atuais, tem-se a tentativa de legitimar direitos que estão sendo conquistados por membros individualmente, como também, a guarda por genitores masculinos e novas configurações familiares. Atualmente, o tema "filiação" traz consigo diversas discussões e debates, pois passa-se a questionar o real significado da expressão "verdadeiro pai" de uma criança e do que seria de fato um pai. Um novo olhar diante desta definição começa a ser descrito, a partir de questionamentos como, de "[...] até que ponto caberia à lei determinar as normas que disciplinam as relações familiares", considerando, a necessidade de profundas modificações no que diz respeito ao Direito de Família (BRITTO, 2008, p.3).

A partir de Britto (2008, p.7) podemos gerar diversas visões no que se direciona a este assunto, como por exemplo, ao poder que a lei exerce no que diz respeito a desconstituição paterna, o que nos remete ao artigo 1.601 do Código Civil Brasileiro onde diz que caberia ao marido o direito de contestar a paternidade dos filhos nascidos da mulher, sendo tal ação imprescritível. Para muitos autores esta seria uma questão conturbada, redirecionado ao fato de que a filiação pode sim ser estabelecida a partir da filiação biológica ou não, decorrendo do fato envolvendo a afetividade.

"Uma coisa é vindicar a origem genética, outra a investigação da paternidade. A paternidade deriva do estado de filiação, independentemente da origem biológica ou não" (Lôbo, 2003, p.153).

Diante de tais assuntos, a atuação da psicologia desperta nas Varas da Família um lugar de grande importância, voltadas a questões envolvendo situações de conflitos envolvendo a guarda dos filhos, guardas compartilhadas, alienação parental envolvendo um dos genitores. O que se torna possível através de conceitos da Psicologia um olhar diferenciado ao sentido da palavra pai e sua vinculação. Desse modo, percebemos a importância e como seria fundamental o estudo interdisciplinar deste tema, para a obtenção de um entendimento maior de suas expressões e conceitos, tendo em vista, um aprofundamento crítico e esclarecimentos da matéria, levando em conta que em cada campo existem suas especificidades e conceitos (Britto, 2008).

\subsection{A Psicologia no contexto Judiciário}

A psicologia foi regulamentada em 1962, pela Lei ${ }^{\circ} 4.119$, relaciona-se a diversas áreas e diferentes linhas teóricas, escolas ou sistemas de base, tendo em vista de que a ciência psicológica possui várias facetas e se expressa por diversas linguagens. Com relação a Psicologia e Direito, pode-se dizer que seriam dois mundos condenados a entender-se, sendo eles ciências que tratam sobre a conduta humana (Trindade, 2010). No que se refere a atuação do psicólogo no campo da Psicologia Jurídica, considera-se que o começo se deu de forma progressivamente lenta, sendo esta, exercida inúmeras vezes de modo informal, mediante trabalhos voluntários, destacando-se que os primeiros trabalhos realizados nesse ramo se deram a partir da área criminal, evidenciando estudos em relação a adultos e adolescentes infratores da lei (Rovinsk, 2002).

Conforme Trindade (2012) os conhecimentos que a psicologia jurídica reporta seriam destacados em duas maneiras: a primeira de acordo com um assessoramento legislativo, ou seja, amparar na elaboração de leis que se adequem a sociedade atual e a segunda sendo o assessoramento judicial, este contribui na organização dos sistema de administração da Justiça. O termo Psicologia Jurídica, seria uma espécie mais ampla, pelo fato deste abranger tanto questões envolvendo fóruns e tribunais, como no âmbito da lei, no que diz respeito à psicologia forense e psicologia legal, termos que eram bastante usuais antigamente.

Entre as definições voltados à Psicologia Jurídica temos que seria um estudo do comportamento dos atores jurídicos no campo do Direito. Já outros remetem a ela, como sendo a psicologia clínica aplicada ao sistema legal, mas tendo em vista de que, atualmente o que vem se consolidando seria de que por mais que a psicologia jurídica utilize da psicologia clínica e da psicopatologia, esta área considera-se própria e autônoma da psicologia no qual provoca um método específico e que não se 
confunde em relação ao ponto de vista clínico. Percebe-se que a Psicologia aplicada juntamente com o Direito seria de suma importância à Justiça, ou seja, para alcançar a justiça, precisa-se de ambos, pois estes compartilham o mesmo objeto que é o homem e no seu bem-estar (Trindade, 2012).

De acordo com Angelim e Ribeiro (2012), o desafio central da Psicologia Jurídica seria a articulação do exercício da subjetividade e a necessidade do Estado de exercer uma espécie de controle social, ou seja, a contribuição dos psicólogos em processos legais requer uma postura interdisciplinar. Esta abrange as dinâmicas sociopolíticas, como também acata o papel do Estado e as condições de exercício da subjetividade em específico no qual está integrada a intervenção realizada, tornando possível a partir do papel do psicólogo no ramo jurídico a obtenção de inovações adequadas diante das demandas atuais da sociedade. Importante destacar que o grande desafio da Psicologia Jurídica seria o de teorizar em relação a importância do Estado, para então validar e amparar a diversidade humana no exercício da subjetividade.

Silva (1999) ressalta um trabalho mais amplo do psicólogo nas Varas da Infância e da Juventude e as Varas da Família, onde os temas centrais são destinados à criança e à família, tornando-se importante destacar o fato de que o psicólogo está trabalhando em uma instituição estatal normativa e por sua vez segue ao código de leis sancionadas pela sociedade. Trindade (2012) destaca a atuação da Psicologia Jurídica como sendo uma contribuição fundamental em questões envolvendo família, direito penal, delitos envolvendo o sexual, demandas de inimputabilidade e na responsabilidade diminuída, em medidas de segurança e no procedimento de Declaração do incidente de insanidade mental, na vitimologia, como também na realização do depoimento com redução de danos, direito penitenciário, direito da criança e do adolescente, entre outros.

Existem inúmeros elementos que compõem a prática da psicologia no âmbito jurídico, o primeiro a ser citado, é o instrumento da Avaliação Psicológica. Este denomina-se como um processo integrativo de investigação sobre um fenômeno psicológico, em diferentes aspectos de expressão. Este é estruturado a partir de dimensões conceptuais, metodológicas, ética e relacional, demarcando um domínio profissional e contribuindo no processamento de tomada de decisões. Em relação à sua perspectiva metodológica, a avaliação psicológica se caracteriza como um conglomerado de estratégias que concedem ao psicólogo instrumentalizar o processo, utilizando ou não de testes psicológicos (Trindade, 2012). Os testes psicológicos são instrumentos de avaliação de uso privativo do psicólogo, que têm o propósito de responder a uma demanda específica, a fim de medir traços ou condições do comportamento humano, sendo elas normais ou patológicas referente à personalidade em geral. Pode-se destacar que no âmbito jurídico considera-se de suma importância, pelo fato de que este conduz uma maior legitimação ao processo (Trindade, 2012).

No que diz respeito ao entendimento do comportamento humano o método mais considerável é a Avaliação psicológica, entre a configuração deste situa-se a perícia psicológica, considerada ainda pouco estudada, mas indispensável em relação a análise de uma pessoa, pois busca a compreensão da identidade e afeição de cada indivíduo, os laudos periciais tem como objetivo investigar de uma forma técnica a fim de mostrar a verdade. Entende-se o trabalho do psicólogo que trabalha no meio jurídico não sendo o de provar a verdade, mas sim nortear circunstâncias presentes na questão familiar que está sendo julgada, onde a partir dela pode se dar a atuação do juiz, promotor, advogado e psicólogo (Gracioli \& Palumbo, 2020).

Outro instrumento utilizado pela área do Direito, no qual foi pautado pelo Conselho Federal de Psicologia mediante da Resolução n 007/2003, são os Documento Psicológicos, estes documentos podem ser públicos ou particulares e contribuem na resolução de conflitos entre o saber científico e o jurídico, revelando o que é acobertado na evidência. (Trindade, 2012). O Conselho Federal de Psicologia (CFP) em sua Resolução CFP nº 06/2019 encontra-se descrita regras para a elaboração de documentos produzidos pelo psicólogo no seu exercício profissional. Discorre na seção II: modalidades de documentos, Art. 8 da nova resolução, constituindo as modalidades de documentos psicológicos como o Atestado Psicológico, Declaração Psicológica, Relatório Psicológico, Laudo Psicológico e por fim o Parecer Psicológico (Conselho Federal de Psicologia, 2019). 


\subsection{Paternidade Sociofetiva}

A temática é demarcada por uma dimensão histórica que remete ao final do patriarcado. A paternidade começa a criar novos horizontes, mudando a figura do chamado pai arcaico, que possuía características fortes como distante, provedor e autoritário para uma concepção mais moderna no qual enaltece a relação/ vínculo de pai e filho, a nova definição de identidade paterna começa a não ser vinculada apenas dentro de uma estimativa apenas biológica (Silva, 1999). No que se refere a um crescimento adequado físico e mental dos indivíduos, se sobressaem a questão das relações que este possui, salientando-se a grande importância da formação dos vínculos na constituição do sujeito, tendo em vista, o afeto como precursor da repersonalização da família, a partir disso começam a surgir de forma natural novas representações sociais e familiares, o que nos leva a Paternidade Socioafetiva, considerada como uma nova concepção familiar, onde possui um lugar de privilégios para uma composição dos afetos, deixando de lado a questão de que a família deve ser concebida de acordo com o núcleo econômico e reprodutivo e direcionando-se para uma dimensão socioafetiva (Trindade, 2012).

Pereira (2015) coloca em evidência em seu artigo a família Nazaré, destacando-a como a primeira e mais expressiva forma de família socioafetiva, pelo fato de José, mesmo não sendo pai biológico de Jesus, o criou como filho, ressaltando que não existe dúvida perante esta paternidade. O Direito brasileiro criou a expressão paternidade socioafetiva afim de representar inúmeras famílias que vivem essa realidade. Considerada uma das categorias da paternidade adotiva, sendo a socioafetividade tendo início com a paternidade e se estendendo à maternidade e a todos os vínculos de parentesco, a partir disso o termo se ampliou à parentalidade socioafetiva.

Aquilo que tradicionalmente chamávamos de posse de estado de filho, complementados pela expressão tractus, fama e nomem, já está reconhecida em dezenas de decisões dos tribunais brasileiros, inclusive no STJ - Superior Tribunal de Justiça com a denominação de socioafetividade. Em 2016 o STF - Supremo Tribunal Federal deve julgar a Ação n. ${ }^{\circ}$ RE 898060-SC, Rel. ${ }^{\circ}$ Luiz Fux, cuja discussão central é a paternidade/maternidade socioafetiva (Pereira, 2015).

Atualmente, as pessoas têm buscado cada vez mais realizar ações voltadas ao seu bem estar e suas relações afetivas, isto fez com que o Estado e os âmbitos jurídicos passassem por adaptações. A partir disso, surgiu um novo conceito, nomeado de Repersonalização, no qual o afeto manifesta sua grande importância, como um elemento nuclear e definidor da união familiar, a fim de aproximar a instituição social com a instituição jurídica. Agora aquilo que antes era apenas tratado pela ciência e a bioética, foi compreendido também pelos juristas, tendo em vista entender e explicar as novas constituições familiares para que a legislação acompanhe em conjunto essa evolução (Souza, 2013).

A psicanálise auxilia nessa nova nomenclatura chamada "parentalidade socioafetiva" pois salienta-se que a paternidade e a maternidade são consideradas funções exercidas. Bem-afamado como um fato de revolução no âmbito jurídico, a parentalidade socioafetiva, amplia a questão paternidade/maternidade socioafetiva, podendo mudar rumos de uma investigação, como podemos exemplificar na questão de partilha de bens, pois uma vez que comprovado a existência de um vínculo socioafetivo, mesmo que não sendo filho biológico, se torna automaticamente um dos herdeiros. Nesta evolução do conceito é possível que a pessoa tenha a possibilidade de ter mais de um pai ou uma mãe, destacando que não necessariamente é excluída a questão da multiparentalidade e a pluriparentalidade. (Pereira, 2015)

Segundo Trindade (2010) o modelo tradicional familiar, constituído por pai, mãe e filhos consanguíneos, baseado como único e correto, consagrou-se desde 1824 a 1988. Com a entrada da comunhão baseada no afeto, essa questão foi a princípio amparada pelos cientistas sociais, educadores, psicólogos como objeto de estudo para suas ciências, o que chamou atenção dos juristas, na busca de uma explicação das novas vinculações familiares contemporâneas. Aos poucos a concepção familiar vai deixando de lado sua natureza institucional jurídica transcorrendo-se para uma compreensão de instrumento de realização pessoal do ser humano, decorrendo da felicidade dos envolvidos no processo de paternidade socioafetiva. 
De acordo com Oliveira (2020) o conceito que está vinculado a palavra "socioafetividade" é de forma literal uma afetividade criada em um contexto social, sendo uma constituição de sociedade familiar fundamentada no afeto. Logo a socioafetividade é o afeto capaz de construir vínculos fortes, ultrapassando a relação de amizade ou carinho respeitoso, tornandose necessária a verificação da existência do animus, ou seja, o interesse, se existe o real interesse da outra pessoa em questão, mesmo não possuindo parentesco consanguíneo. Destacando-se que atualmente é um termo considerado recente e que em decorrência disso sua aplicação na esfera jurídica continua sob adaptações.

Consideramos a socioafetividade como uma afetividade que possui a capacidade de formar laços familiares, tendo a partir a criação de parentescos, no que envolve consequentemente obrigações diante dessa paternidade socioafetiva em base da legislação civil apropriada (Oliveira, 2020). Segundo Lôbo (2006), houve uma grande evolução diante do processo a respeito do que a doutrina jurídica especializada designa como Paternidade e filiação socioafetiva, sendo esta, baseando-se na convivência familiar, excluindo a origem da criança. Pode-se compreender duas realidades observáveis diante desse contexto, uma seria a integração definitiva da pessoa no grupo familiar e a outra de acordo com a relação afetiva tecida no tempo entre que assume os papéis de pai e filho, estes realidades seriam anteriormente permanentes, não tendo nenhuma relação, mas devido a mudança no direito brasileiro, que se deu a partir da Constituição de 1988.

O afeto, com ou sem vínculos biológicos, deve ser sempre o prisma mais amplo da família, longe da velha asfixia do sistema patriarcal do passado, sempre em prol da dignidade humana. Sabido é que os sistemas legais do passado não tinham compromisso com o afeto e com a felicidade (Venosa, 2017, p.8).

Oliveira (2020) faz uma analogia em questão da adoção e paternidade socioafetiva, pelo fato de as duas temáticas envolverem a área jurídica e filiação. Todavia a paternidade socioafetiva difere pelo fato de o desenvolvimento da filiação afetiva já existir anteriormente da efetivação judicial da paternidade, ou seja, duas pessoas no qual já teriam uma convivência familiar e apenas estão em busca da validação jurídica. A paternidade socioafetiva é considerada como uma conquista, pelo fato de ter originado modificações na legislação contemporânea, podendo assim adequar a transfiguração sucedida através dos institutos familiares, sendo apontada como um dos maiores exemplos envolvendo a evolução sociológica. Posteriormente, começa-se a ser assimilado dentre as pessoas, que a relação de pai e filho vai muito além de uma filiação biológica, tampouco jurídica, se desenvolvendo a partir do vínculo criado pelo afeto entre ambos (Gracioli \& Palumbo, 2020).

A parentalidade refere-se aos vínculos, laços que se desenvolvem, caracterizando para a criança uma representação estruturante na vida psíquica, acolhendo-a e respondendo às necessidades físicas como também emocionais (Zimerman \& Coltro, 2010). Salienta-se que a Parentalidade Socioafetiva tenha inúmeros pontos positivos para a criança, mas é importante ressaltar que podem apresentar alguns riscos envolvendo seus aspectos psíquicos, esses se não forem valorizados, podem colocar a criança em uma situação traumática, ou seja, não iria suprir a falta do pai/mãe e sim poderia reativar dores passadas, como, por exemplo, o abandono de seus pais biológicos.

A verdadeira paternidade não pode se circunscrever na busca de uma precisa informação biológica; mais do que isso, exige uma concreta relação paterno-filial, pai e filho que se tratam como tal, donde emerge a verdade sócio-afetiva. Ademais, a verdadeira paternidade ou maternidade decorre mais amar e servir do que fornecer um material genético (Zimerman \& Coltro, 2010).

Após uma análise teórica envolvendo o tema de Paternidade Socioafetiva, a fim de exemplificar de forma concreta, e poder esclarecer a partir de uma jurisprudência, como o sistema judiciário está resolvendo questões envolvendo essa temática, foi feita uma pesquisa no site do Tribunal de Justiça. A seguir serão apresentadas decisões do Tribunal de Justiça de São Paulo (TJSP).

No caso concreto escolhido, tem-se: 
RECONHECIMENTO DE PATERNIDADE SOCIOAFETIVA E ALIMENTOS. ELEMENTOS DOS AUTOS QUE COMPROVAM SATISFATORIAMENTE OS FATOS ALEGADOS NA INICIAL - MENOR QUE CONVIVEU COM O RÉU DESDE TENRA IDADE - MANUTENÇÃO, AINDA DE FORTES VÍNCULOS DE AFETIVIDADE ENTRE AS PARTES, apesar dos ressentimentos decorrentes da separação do casal. atendimento do princípio da dignidade humana e da preservação dos vínculos afetivos e da solidariedade. ação julgada procedente, fixada a pensão alimentícia no valor correspondente a $30 \%$ do salário mínimo, à ausência de prova efetiva dos rendimentos do réu. RECURSO do autor PROVIDO. (São Paulo, 2020).

Inicialmente a mãe, como representante do filho, entrou com a Ação de Paternidade Socioafetiva, no qual foi julgada procedente em primeiro grau, que posteriormente entrou com recurso onde foi julgado improcedente. Em resumo, o réu conviveu com o autor desde os três meses até os dez anos de idade, pois este teria um relacionamento com a mãe do menino. O réu assumiu o papel de pai do autor, estabeleceu vínculos fortes, sendo relato que em três anos de convivência o réu declarou o enteado como seu dependente no Cartório de Registro Civil. Discorre que após ter aceitado uma proposta de trabalho em outra cidade e o rompimento com a genitora, foi declarado que o filho foi abandonado, pelo fato de que o considerava como sua única figura paterna, sendo descrito que por exigência deste a mãe nunca localizou o seu pai biológico (São Paulo, 2020).

Conceitua-se a paternidade socioafetiva como um vínculo estabelecido através do reconhecimento social e afetivo entre um homem e uma criança que através do afeto produzido, se tornam pai e filho, não contendo vínculo biológico ou adotivo. Apesar de atualmente o vigor do Código Civil exclusivamente reconhecer o parentesco de sangue ou adoção. Ao prenunciar uma inovação, a legislação civil, diante do artigo 1.593, declara que o parentesco é natural ou civil, de acordo com a consanguinidade ou diversa origem, sendo considerado pelo Enunciado n. 256 do Conselho de Estudos Judiciários do Conselho da Justiça Federal (CEJ) que a posse do estado de filho, ou seja a parentalidade socioafetiva, constitui-se pela modalidade de parentesco civil (São Paulo, 2020).

O psicólogo através da avaliação feita com a criança, onde foram utilizados os instrumentos de entrevistas e observação, comprovou a presença real de um vínculo socioafetivo, pela relação que construíram durante os anos de convivência. Considerando diante de um olhar social, como consequência desta separação foi produzido danos psicológicos no autor, pela mágoa que foi elaborada neste momento. Por conseguinte, o psicólogo Jurídico responsável pelo caso, concluiu a existência de uma vinculação afetiva do réu com o autor, e garantiu que por mais que o menino tivesse mágoas do requerido por não tê-lo reconhecido, ainda o vê como pai (São Paulo, 2020).

A Posteriori a comprovação do caso, torna-se clara a relação de paternidade socioafetiva por parte do requerido, excluindo a intervenção desta relação diante o término da mãe do autor com o réu e dando ao atualmente adolescente de dezessete anos o direito da paternidade socioafetiva e da pensão alimentícia. Pelo fato de que mesmo a filiação mesmo não constando no ordenamento jurídico brasileiro, não está totalmente vulnerável, devido aos requisitos que autorizam seu reconhecimento, sendo intitulado a todos os direitos e deveres específicos para além das filiações existentes (São Paulo, 2020).

\section{Considerações Finais}

O motivo pela escolha da temática de Parentalidade Socioafetiva, surgiu pelo meu interesse particular sobre a Psicologia Jurídica e suas particularidades, afim de aperfeiçoar os meus conhecimentos sobre a área e compartilhar esses contextos jurídicos no qual a psicologia está inserida. Assim como foi discorrido em meu trabalho, essa é uma temática ainda considerada nova no âmbito jurídico e a trouxe com a finalidade de colocar em ênfase e em discussão o que antes era apenas voltados a leis, agora sendo tratada e analisada com empatia.

Levando em consideração as pesquisas realizadas para a composição deste artigo, pode-se concluir a importância da atuação da Psicologia como ciência, no qual relaciona-se em diversas áreas e linhas teóricas. Dando ênfase nos sistemas judiciários, a psicologia jurídica desde os primórdios foi exercida de forma gradual, mas atualmente tem se demonstrado mais 
eficaz, em decorrência das mudanças sociais e que ainda continuam em evolução. O setor Jurídico teve que se readaptar para conseguir dar conta das novas demandas que estavam sendo discutidas, principalmente na área do Direito de Família, o que fez com que assuntos envolvendo as relações, vínculos, papeis e filiação tivessem um novo olhar, possibilitando uma conquista e um espaço ainda maior para a Psicologia no âmbito jurídico.

Essas mudanças só foram possíveis a partir do momento em que a vinculação e o afeto se tornaram evidentes para o setor jurídico, sendo imprescindível na área do direito de Família, antepondo a filiação biológica, pelo fato de que o afeto vindo dos pais seria um dos elementos mais importantes para a formação de uma personalidade humana saudável. Assim, a parentalidade socioafetiva, entra em discussão de diversas maneiras no âmbito jurídico, com o abandono afetivo, questões envolvendo guardas, bem como o direito sucessório, no qual após comprovação de um vínculo socioafetivo a criança será reconhecida e terá os mesmos direitos que os filhos biológicos, tal como a herança. Ressaltando o caso de pensões alimentícias, que foi citado acima, descrito de uma jurisprudência. Considera-se fundamental a constante busca por estudos envolvendo essa área, pois mesmo que esse tema exista há muito tempo, ainda julga-se escassa a sua discussão e sua reflexão, sendo reconhecido como um temática contemporânea.

\section{Referências}

Angelim, F. \& Ribeiro, M. (2012). Psicologia Jurídica: o exercício da subjetividade e a necessidade de controle do Estado. Psicologia, Ciência e ProfissãoDiálogos. Conselho Federal de Psicologia. 9(8).

Bastos, A. B. B. I. (2010). A técnica de grupos-operativos à luz de Pichon-Rivière e Henri Wallon. Psicol inf. 14(14), 160-9.

Brito, L. M. T. (2008). Paternidades Contestadas: a definição da paternidade como um impasse contemporâneo - Editora Del Rey.

Conselho Federal De Psicologia. Resolução $\mathrm{n}^{\circ}$ 16, de 29 de março de 2019. Institui regras para a elaboração de documentos escritos produzidos pela(o) psicóloga(o) no exercício profissional e revoga a Resolução CFP $n^{o}$ 15/1996, a Resolução CFP $n^{o}$ 07/2003 e a Resolução CFP $n^{o}$ 04/2019. https://atosoficiais.com.br/cfp/resolucao-do-exercicio-profissional-n-6-2019-institui-regras-para-a-elaboracao-de-documentos-escritos-produzidos-pela-opsicologa-o-no-exercicio-profissional-e-revoga-a-resolucao-cfp-no-15-1996-a-resolucao-cfp-no-07-2003-e-a-resolucao-cfp-no-04-2019?q=006/2019 .

Costa, J. (2009) Paternidade socioafetiva social-affective paternity- Revista Jurídica - CCJ/FURB ISSN 1982 -4858. 13(26), 127-140.

Gracioli, S. M. A. \& Palumbo, L. P. (2020). A Importância da Psicologia Jurídica e a Aplicação de Laudo Psicológico como motivação de Decisões Judiciais no Direito de Família Brasileiro. The Importance of Legal Psychology and the Application of a Psychological Award as a motivation for Judicial Decisions in Brazilian Family Law. https://www.brazilianjournals.com/index.php/BRJD/article/view/19954/1598 .

Lôbo, P. L. N. (2006). Paternidade Socioafetiva e a Verdade Real. Revista CEJ, 34, 15-21.

Lôbo, P. L. N. (2003). Código Civil Comentado- V. Xvi: Direito de Família. Relações de Parentesco. Direito Patrimonial- Artigos 1.591 a 1693. Atlas S.A, vol. 16.

Martín-Baró, I. (1997). O papel do Psicólogo. Estudos de Psicologia (Natal) 2(1), 7-27. https://doi.org/10.1590/S1413-294X1997000100002.

Oliveira, L. C. M. (2020). Multiparentalidade e Parentalidade Socioafetiva- efeitos. https://www.ibdfam.org.br/artigos/1506/Um ltiparentalidade+ e+parenta lidade+socioafetiva+\%E2\%80\%93+efeitos.

Pereira, R. da C. (2015). A família de Nazaré e a Parentalidade Socioafetiva. https://ibdfam.org.br/artigos/1087/A+f am\%c3\%adlia+de+Nazar\%c3\%a9+e+a+parentalidade+socioafetiva.

Rovinski, S. L. R. (2002). La psicologia jurídica en Brasil. In: Tratado de psicología forense (pp.661-665). Madrid: Siglo Veintiuno de España Editores.

Rother, E. T. (2007). Revisão Sistemática X Revisão Narrativa. Revista Acta Paulista de Enfermagem (online), São Paulo, 20(2).

São Paulo. Tribunal de Justiça (27. Câmara de Direito Privado). Apelação Cível no 1000748-09.2014.8.26.0007, da Comarca de São Paulo, em que são apelantes M. S. DE M. (REPRESENTANDO MENOR(ES)) e Z. M. S. J. (MENOR(ES) REPRESENTADO(S)), é apelado R. F. DE M. https://esaj.tjsp.jus.br/cjsg/getArquivo.do;jsessionid=FAB7F365E2193B3809FFEFC447564C04.cjsg2? conversationId=\&cdAcordao=13928 852\&cdForo=0\&u uidCaptcha=sajcaptcha_f05b12dcfe4e4c52a2bf0e4536b64c63\&g-recaptcha-response=03AGdBq27cxvmqnloAm15L-Oh5iVZmyvn jZMQqTDPvPT5C CvyP UqFb8 GaXYFeyaoGPJAuYdRKtgZNqOm8-qWbB20R--Q1C9jXfPBGod19mZIWCT ILo0IRcVT4uAobQ1CRUTxg0SKwlzq917uhhjfJQnWvmn oHR_A0 aZdLK_YUsLAiQyKAx7bcTafPCHCGeiej-j1Qe0Ggag5FK072eEPyNpbW-XdMuv_VXg7jJ51k3PvMpllM8Wso71HdSXipbup1igIigNh U28wonN FqpiQd K9z WBx3w_us8C5N66P3h8irP4RptOG92I23DGF366fvPHEDAWgxPsd7qieN196kDrfE9YHFB6QyRTW2m2iL_Cvah6M8mjO30RGdRvmGMhEEf LE _7nIslPP077rkydcAGvNkmXr_7sl4v8v0RIHADHDF2os3QPFUv3r15uIIgSqTAtIzoWO2Ds6fWPDnsdaBs5WHYvSE0BU8wCiFCHCIsgzkwxxWBEqQLO ZW_b3jRho33fE6-7OaRht6HB

Silva, E. Z. M. (1999). Paternidade ativa na separação conjugal. Editora Juarez de Oliveira. 
Research, Society and Development, v. 10, n. 10, e456101018581, 2021

(CC BY 4.0) | ISSN 2525-3409 | DOI: http://dx.doi.org/10.33448/rsd-v10i10.18581

Silva, E. Z. M. \& Rovinski, S. L. R. (2012). Família no Judiciário. Organizadores; Baptista, M. N. \& Teodoro, M. L. M.- Psicologia da Família: teoria, avaliação e intervenções. Porto Alegre: Artemed.

Souza, P. F. P. (2013). A relevância do princípio da afetividade nas relações familiares. Porto Alegre, 30 p., Trabalho de Conclusão de Curso apresentado como requisito parcial à obtenção do grau de Bacharel em Direito. Pontifícia Universidade Católica do Rio Grande do Sul.

Trindade, J. (2010). Manual de psicologia jurídica para operadores do direito (4a ed). Livraria do Advogado.

Trindade, J. (2012). Manual da Psicologia Jurídica para operadores do Direito (6a ed). Livraria do advogado Editora.

Universidade Estadual de São Paulo, Campus Botucatu. (2015). Tipos de Revisão de Literatura.

Zimerman, D. \& Coltro, A. (2010). Organizadores. Aspectos Psicológicos na prática jurídica: obra completa (3a ed) Millennium Editora. 